\title{
Daya Saing Usaha Mikro Kecil : Modifikasi Porter Diamond Model
}

\author{
LITA APRIANI RUSTIAN \\ TANTRI WIDIASTUTI \\ Sekolah Tinggi Ilmu Ekonomi Widya Manggala \\ Jalan Sriwijaya No.32 \& 36 Semarang 50242 \\ Email: litaaprianirustian@gmail.com
}

Diterima 23 September 2020; disetujui 20 September 2020;

\begin{abstract}
This study aims to analyze: (1) the effect of production factors on competitiveness; (2) the effect of demand conditions on daylight power (3) the effect of related and supporting industries on competitiveness (4) the effect of production factors, demand conditions and related and supporting industries on competitiveness. Respondents in this study were 90 micro and small businesses that became partners of Pusat Layanan Usaha Terpadu (PLUT) in the Special Region of Yogyakarta. The variables used in this research are related and supporting industrial cooperation as independent variables, production factors, demand conditions, competitiveness as the dependent variable. Data collection using questionnaires and data analysis using multiple linear regression analysis. The results of the research are showed that, production factors have an effect on MSE competitiveness of $6.05 \%$, demand conditions of $11.28 \%$ and related and supporting industries of $8.58 \%$.
\end{abstract}

Keywords: Production Factors, Demand Conditions, Related and Supporting Industries, Competitiveness.

\section{PENDAHULUAN}

Latar Belakang. Usaha Mikro Kecil Menengah memiliki peranan yang penting dalam perekonomian (Nagayya \& Tirumala Rao, 2013). UMKM atau UKM berperan dalam pertumbuhan ekonomi. Hal senada dikemukakan oleh Darwanto (2013) yang menyebutkan bahwa UMKM menyerap tenaga kerja, menyumbang devisa dan berkontribusi pada pendapatan daerah. Chosniel et al. (2014) menyatakan bahwa UMKM merupakan tulang punggung sektor swasta pada semua negara berkembang.
Sedangkan Fitriati (2015) menyatakan bahwa UMKM terbukti memberikan kontribusi terhadap perkembangan perekonomian bangsa. Mengingat pentingnya UMKM, maka diperlukan suatu upaya untuk menjaga kelangsungan usaha di tengah persaingan yang semakin meluas.

Usaha yang bisa dilakukan untuk dapat bertahan dalam persaingan, membutuhkan daya saing termasuk di dalamnya berkompetisi untuk mengambil bagian dari pasar (Shibia \& Barako, 2017). Pertumbuhan UMK harus didorong agar dapat menciptakan lebih banyak pekerjaan. 
Peranan UMK dalam perekonomian tidak terlepas dari tantangan yang harus dihadapi, terlebih lagi pada era global sekarang ini. Hal tersebut sesuai dengan pendapat Wiyadi (2009) yang menyatakan bahwa globalisasi menghilangkan batas ekonomi negara di dunia, sehingga muncul tantangan dari dalam maupun luar negeri yang harus dihadapi dalam dunia bisnis. Persaingan bisnis dari meluasnya pasar tidak dapat ditolak tetapi harus dihadapi dengan cara memperkuat bisnis, menciptakan bisnis yang berdaya saing.

Peningkatan daya saing membutuhkan kerjasama dari semua aspek, akademisi, pemerintah dan pelaku usaha itu sendiri. Kaitannya dengan hal tersebut dibutuhkan pula perhatian pada komponen-komponen yang mendukung daya saing. Salah satu model pengukuran daya saing yaitu dengan memperhatikan 4 (empat) komponen yang terdiri dari faktor kondisi, kondisi permintaan, industri terkait dan pendukung, strategi, struktur dan persaingan. Model tersebut di kenal dengan Porter diamond model. Penggunaan model yang diperkenalkan oleh Porter telah dilakukan oleh beberapa peneliti dan model tersebut juga memperoleh kritik, salah satunya oleh Eickelpasch et al. (2011) yang mengkritik tentang tingkat abstraksinya yang tinggi dan ambiguitas manifestasi hubungan yang diusulkan, yaitu, pergeseran Porter dalam menjelaskan keunggulan kompetitif atau daya saing pada berbagai skala konseptual: bangsa, industri, perusahaan individu, atau pada tingkat regional dan lokasi. Selain itu, Porter mengklaim bahwa semua aspek dalam model berinteraksi dan saling menguatkan tetapi, pada kenyataannya, model tidak secara eksplisit memasukkan variabel independen, setiap variabel terkait dengan variabel lain, sehingga terdapat ambiguitas hubungan antar variabel, jadi dibutuhkan modifikasi dari Porter diamond model.

Penelitian ini akan mengambil setting penelitian pada UMKM di provinsi DIY. Alasan pemilihan provinsi DIY sebagai setting penelitian adalah karena UMKM menyumbang 95 persen perekonomian DIY. Namun di sisi lain, daya saing UMKM di provinsi DIY masih rendah..

Tujuan Penelitian. Tujuan penelitian ini yaitu menganalisis pengaruh faktor produksi, kondisi permintaan dan industri terkait dan pendukung terhadap daya saing dengan melakukan modifikasi pada Porter Diamond Model.

\section{TINJAUAN TEORETIS}

Porter Diamond Model. Michael Porter membuat model untuk pengukuran daya saing yang disebut sebagai Porter Diamond Model. (Porter, 1990) mengemukakan mengenai konsep dasar daya saing bukan diwariskan tetapi diciptakan.

Model tersebut menggambarkan hubungan yang saling terkait antar variabel yang ada dan tidak ada kejelasan mengenai variabel bebas ataupun variabel terikat. Hubungan yang ditunjukkan oleh model tersebut mengartikan bahwa semua variabel adalah terikat sehingga menimbulkan kebingungan. Porter melakukan penelitian terkait daya saing pada sepuluh negara utama dalam perdagangan menggunakan diamond model. Cho dan Moon (2003:73) "Porter menyimpulkan bahwa beberapa negara berhasil dalam industri tertentu karena lingkungan asalnya bersifat forwardlooking, dinamis, dan menantang. Secara spesifik, beberapa penentunya adalah kondisi faktor, kondisi permintaan, industri terkait dan pendukung, strategi perusahaan, struktur dan persaingan". Model Porter tidak 


\section{Gambar 1}

\section{Porter Diamond Model}

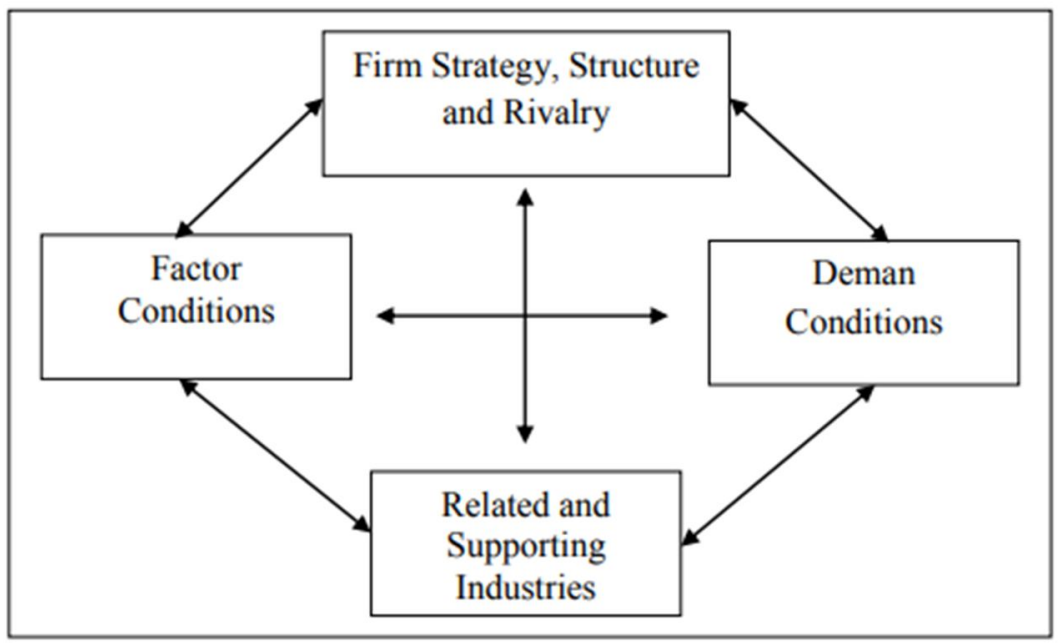

Sumber: (Porter, 1990:78)

terlepas dari kritik, (Eickelpasch et al., 2011) banyak kritik terkait model diamond Porter, yang paling mendasar yaitu kritik terkait hubungan variabel yang ambigu.

Berdasarkan kritik tersebut, dilakukan modifikasi terhadap diamond Porter yang dapat digunakan untuk mengukur daya saing suatu perusahaan. Berikut adalah model modifikasi oleh Eickelpasch dapat dilihat pada gambar 2. Selain Eickelpasch penelitian dengan modifikasi diamond Porter juga dilakukan oleh Bakan \& Dogan, yang ditunjukkan pada gambar 3. Bakan dan Dogan melakukan modifikasi dengan menjadikan variabel strategi, struktur dan persaingan sebagai variabel dependen, menambah peran pemerintah sebagai variabel independen sesuai dengan model Porter yang baru. Penelitian yang dilakukan tersebut bertujuan untuk menguji pengaruh dari variabel (faktor kondisi, kondisi permintaan, industri terkait dan pendukung serta peran pemerintah) berdasarkan model yang dikembangkan oleh Porter terkait daya saing.

Faktor Produksi. Faktor produksi dalam hal ini yaitu berkaitan dengan UMKM, jadi pelaku usaha bukan menurunkan tetapi menciptakan faktor produksinya sendiri. Faktor-faktor dasar seperti kumpulan tenaga kerja atau sumber bahan mentah lokal, tidak menyatakan keunggulan dalam industri padat pengetahuan. Perusahaan dapat mengaksesnya secara mudah melalui strategi global atau memotongnya melalui teknologi. Untuk mengukur faktor kondisi (Wiyadi, 2009) menggunakan unsur-unsur sebagai berikut: (a) sumber bahan baku, (b) sumber tenaga kerja, (c) sumber modal, (d) teknologi, (e) lokasi, (f pengetahuan, (g) biaya produk. Pada penelitian ini, mengadopsi unsur-unsur tersebut dengan merubah sumber tenaga kerja menjadi sumber daya manusia karena ruang lingkup sumber tenaga kerja dirasa lebih sempit dan penelitian ini ingin mengetahui kondisi sumber daya manusia pelaku usaha dengan adanya pelatihan atau seminar yang diikutinya, selanjutnya menghilangkan unsur lokasi, karena sekarang sudah ada penjualan sistem online, pengetahuan, sudah termasuk dalam kondisi sumber daya manusia dan biaya produk dapat terlihat dari pengadaan bahan baku. 


\section{Gambar 2}

\section{Pengembangan Model Diamond Porter}

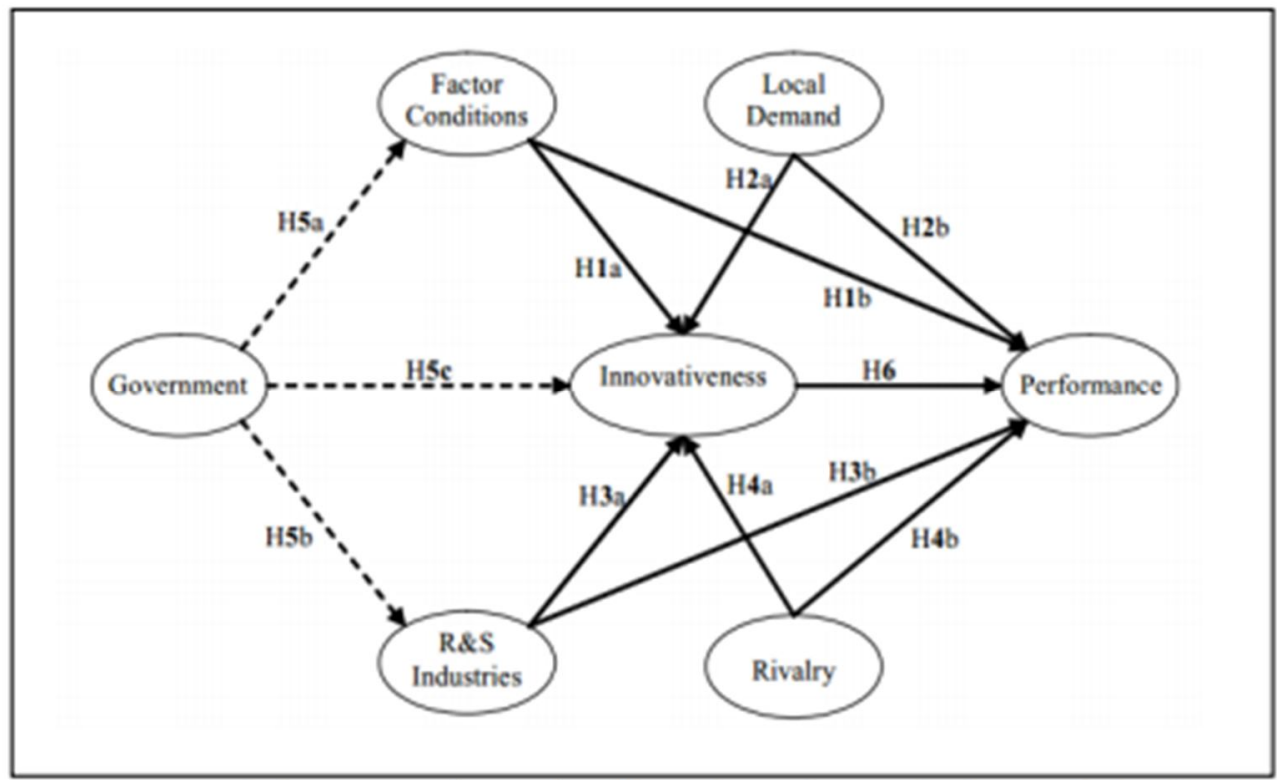

Sumber: (Eickelpasch et al., 2011)

\section{Gambar 3}

\section{Modifikasi Porter diamond model}

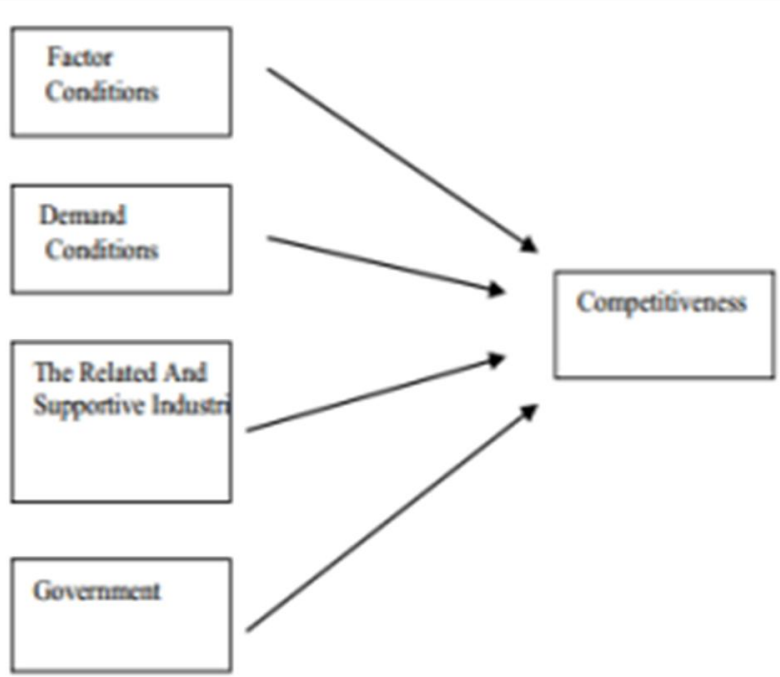

Sumber: (Bakan \& Doğan, 2012)

Kondisi Permintaan. Porter (1990) "the nature of home market demand for the industry's product or service”. Permintaan regional dapat mendorong perusahaan untuk lebih berinovasi sehingga lebih berdaya saing. (Chosniel et al., 2014) mengemukakan bahwa tantangan yang dihadapi saat ini yaitu mengenai bagaimana UKM dapat berpartisipasi di pasar global dengan cara yang mengarah pada keuntungna yang berkelanjutan. (Molamohamadi et al., 2013) menyatakan permintaan dari pelanggan menjadi stimulus untuk rantai pasokan sehingga membuat perusahaan focus untuk menghasilkan barang yang dibutuhkan oleh pelanggan. (Viederyte \& Didziokas, 2014) 
"meeting and identifying the demand of customers will help cluster firms to compete more successfully in global markets". Berdasarkan kedua pendapat tersebut perrmintaan pelanggan dapat membantu usaha untuk bersaing. Hal yang sama juga dikemukakan oleh (Gupta et al., 2016) “....the competitiveness of a firm can enable its managers to innovate their marketing practices". (Cho \& Moon, 2003) mengemukakan para pembeli yang berpengalaman dan memiliki permintaan akan memberikan suatu jendela ke dalam kebutuhan pelanggan maju; mereka menekan perusahaan untuk memenuhi standar yang tinggi; mereka mendorong perusahaan untuk melakukan perbaikan, berinovasi, dan melakukan pembaharuan ke dalam segmen yang lebih maju. Kondisi permintaan diukur menggunakan unsur-unsur sebagai berikut: (a) segmen pasar, (b) akses pasar, (c) pengembangan pasar (Wiyadi, 2009).

Industri Terkait dan Pendukung. Kerjasama industri terkait dan pendukung akan terus berlangsung dan mencapai tujuan jika antara pihak yang bekerjasama saling saling membangun kepercayaan, hal itu sesuai yang dikemukakan oleh (Tanguy, 2016) yaitu pembentukan kepercayaan di antara para mitra menjadi unsur penting untuk sukses. Kerjasama dengan industri tekait dapat membawa pada keberhasilan usaha, hal itu sesuai dengan yang dikemukakan oleh Global Institute of Flexible Systems Management (2018) "cooperation within networks and constellations is one such arena of high relevance". Pada penelitian ini, industri terkait dan pendukung diukur menggunakan unsur-unsur sebagai berikut: (a) penyedia bahan baku, (b) lembaga keuangan dan (c) media promosi (Porter, 1990)

Strategi Perusahaan, Struktur, dan Persaingan (Daya Saing). Pada konteks perusahaan atau usaha, strategi perusahaan, struktur dan persaingan menggambarkan bagaimana perusahaan dibuat, diatur, dikelola dan bagaimana persaingannya dengan usaha lain. (Srinivasan, 2014) Porter berpendapat struktur industri memiliki pengaruh kuat dalam menentukan aturan permainan yang kompetitif yang akhirnya memberikan keuntungan bagi industri. Pentingnya strategi juga dikemukakan oleh (Gautam \& Singh, 2011) industri perlu merancang strategi yang kompetitif dalam menjalankan bisnis. Strategi itu sendiri berkaitan dengan bagaimana cara yang dilakukan untuk mencapai tujuan, sesuai dengan pendapat (Mishra, 2013) "Strategy is concerned with how one applies one's resources to achieve one's aims".

Strategi yang efektif harus dilakukan untuk keberlangsungan pertumbuhan usaha. Strategi tersebut berkaitan dengan cara mengatur organisasi dan persaingan, sesuai yang dikemukakan oleh (Viederyte \& Didziokas, 2014) faktor ini mengacu pada kondisi yang mengatur organisasi perusahaan dan aspek peraingan di antara strategi perusahaan. (Wiyadi, 2009) menggunakan unsur-unsur seebagai berikut: (a) ancaman pendatang baru, (b) penyesuaian, (c) strategi bersaing, (d) inovasi, (e) kemampuan manajerial, (f) fleksibiltas. Pada penelitian ini menghilangkan unsur strategi bersaing, penyesuaian dan fleksibilitas karena termasuk di dalam kemampuan manajerial dan inovasi, selain itu mengganti ancaman pendatang baru dengan pesaing usaha.

Penelitian Terdahulu. Ada beberapa penelitian yang berkaitan dengan daya saing, (Bakan \& Doğan, 2012) dengan judul Competitiveness of The Industries Based on The Porter's Diamond Model: An Empirical Study. Bakan dan Dogan meneliti industri pada sektor utama yang berperan penting di provinsi Kahramanmaras yang terdiri dari: 
tekstil, makanan, peralatan dapur dan perhiasan. Diperoleh hasil penelitian bahwa: the conditions of demand affect the sectors competitiveness more than any other factors in diamond model. Hasil penelitian tersebut menunjukkan, kondisi permintaan memberi pengaruh utama pada daya saing, kedua peran pemerintah, selanjutnya industri terkait dan pendukung, yang terakhir yaitu faktor kondisi. Penelitian Bakan dan Dogan merubah variabel strategi perusahaan, struktur dan persaingan menjadi daya saing, penelitian ini juga melakukan hal tersebut. Perbedaannya, peran pemerintah pada penelitian Bakan \& Dogan dijadikan variabel tersendiri, pada penelitian ini dimasukan pada aspek-aspek variabel karena dalam hal ini pemerintah memiliki peran dalam penciptaan daya saing melalui Pusat Layanan Usaha Terpadu.

(Lantu et al., 2016) dengan judul Pengembangan Model Peningkatan Daya Saing UMKM di Indonesia: Validasi Kuantitatif Model. Hasil yang diperoleh dari penelitian tersebut yaitu terdapat enam variabel utama yang membentuk daya saing UMKM suatu provinsi, antara lain: ketersediaan dan kondisi lingkungan usaha, kemampuan usaha, kebijakan dan infrastruktur, riset dan teknologi, dukungan finansial dan kemitraan, serta variabel kinerja. Variabel-variabel yang diperoleh dari hasil penelitian tersebut memiliki persamaan dengan Porter Diamond Model yang digunakan pada penelitian ini, variabel ketersediaan dan kondisi lingkungan usaha, kemampuan usaha, kinerja, berhubungan dengan dimensi kondisi faktor, variabel kebijakan dan infrastruktur, riset dan teknologi berhubungan dengan dimensi strategi perusahaan, struktur dan persaingan, selanjutnya dukungan finansial dan kemitraan, berhubungan dengan dimensi industri terkait dan pendukung. Kondisi permintaan tidak ada pada penelitian yang dilakukan oleh Lantu. Pada penelitian ini, untuk melihat daya saing UMKM dilihat juga dari segi kondisi permintaan.

(Kharub \& Sharma, 2016) dengan judul Investigating the role of Porter Diamond Determinants for Competitiveness in MSMEs. Penelitian tersebut menggunakan analisis deskriptif untuk menghitung daya saing dari faktor-faktor yang ada pada model diamond Porter. Pada penelitian ini, dilakukan modifikasi terhadap model Porter dan setelah itu baru dihitung daya saing. Hasil penelitian Kharub menunjukkan faktor produksi seperti teknologi, infrastruktur, sumber daya manusia memiliki pengaruh untuk membangun kondisi daya saing perusahaan.

Kerangka Teoretis. Kerangka teoretis menjadi acuan berpikir dan acuan dalam mengambil tindakan, tindakan yang diambil dari penelitian ini yaitu menjelaskan permasalahan tentang daya saing UMK. Model yang digunakan dalam menjelaskan daya saing yaitu Porter diamond model. Terdiri dari 4 (empat) variabel, yaitu: faktor kondisi, kondisi permintaan, industri terkait dan pendukung, yang terakhir yaitu strategi perusahaan, struktur dan persaingan. Pada penelitian ini faktor kondisi dipertegas menjadi faktor produksi dan menjadikan strategi perusahaan, struktur dan persaingan sebagai daya saing.

Penelitian yang dilakukan Eickelpasch et al. serta Bakan \& Dogan dilakukan dengan memodifikasi diamond Porter, pada penelitian ini ingin mengetahui pengaruh sesuai variabel yang ada pada model terhadap daya saing. Mengacu pada modifikasi yang dilakukan oleh Bakan \& Dogan, strategi, struktur dan persaingan dijadikan sebagai variabel daya saing. Hal tersebut sesuai dengan teori Porter sendiri karena menurut Porter daya saing diciptakan 
melalui inovasi. Variabel kondisi faktor dalam penelitian ini diperjelas menjadi faktor produksi, selanjutnya variabel kondisi permintaan serta industri terkait dan pendukung. Ketiga variabel tersebut dijadikan sebagai variabel independen, sedangkan strategi perusahaan, struktur dan persaingan sebagai variabel dependen. Berdasarkan penjelasan tersebut, maka kerangka berpikir yang digunakan dalam penelitian ini dapat dilihat pada gambar 4 .

Hipotesis. Berdasarkan landasan teori dan penelitian terdahulu, maka hipotesis yang akan dibangun dalam penelitian ini adalah: Faktor produksi, kondisi permintaan, industri terkait dan pendukung berpengaruh terhadap daya saing.

\section{METODE PENELITIAN}

Jenis Penelitian. Penelitian ini merupakan penelitian expost facto dengan pendekatan kuantitatif.

Populasi dan Sampel. Penelitian ini dilakukan pada Usaha Mikro Kecil yang menjadi mitra binaan PLUT DIY dan aktif mengikuti layanan dan kegiatan yang diberikan oleh PLUT selama bulan Januari Juni 2018 yang berjumlah 90 pelaku usaha.
Metode Pengumpilan Data. Metode pengumpulan data pada penelitian ini yaitu menggunaikan kuesioner yang dengan menggunakan 4 (empat) skala likert, dokumentasi untuk mengetahui jumlah da nama usaha yang menjadi mitra binaan, serta metode wawancara yaitu digunakan pada pendahuluan untuk mengumpulkan informasi awal.

Teknik Analisis Data. Setelah data terkumpul, data akan dianalisis menggunakan analisis regresi berganda.

\section{HASIL DAN PEMBAHASAN}

Analisis Regresi Linear Berganda. Hasil analisis regresi linear berganda dapat dilihat pada tabel 1. Berdasarkan hasil regresi pada tabel 1, dapat diperoleh persamaan regresi sebagai berikut:

$$
\begin{aligned}
\mathrm{Y}= & -5.972+0,198 \mathrm{X} 1+0,367 \mathrm{X} 2+ \\
& 0,374 \mathrm{X} 3+\mathrm{e}
\end{aligned}
$$

Uji Hipotesis. Berdasarkan output regresi pada tabel 1, dapat dilakukan uji hipotesis sebagai berikut: tingkat signifikansi faktor produksi sebesar 0,021. Tingkat signifikansi yang diperoleh kurang dari 0,05,

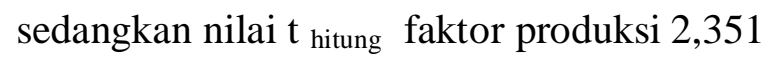
lebih besar dari $\mathrm{t}$ tabel sebesar 1.987,

Gambar 4

Kerangka Teoretis

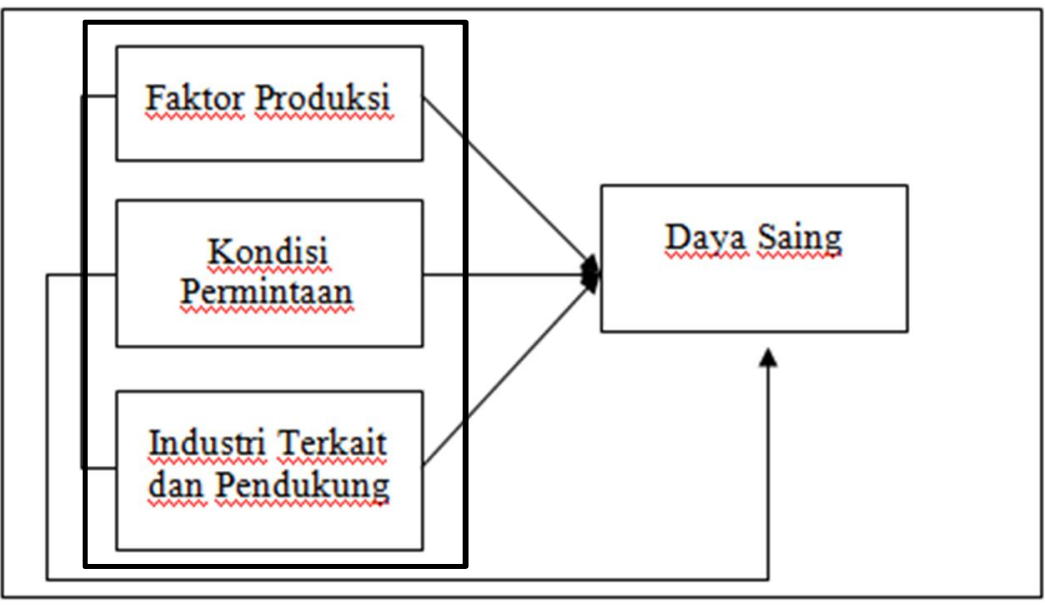


Tabel 1

Analisis Regresi Berganda

\begin{tabular}{|c|c|c|c|c|c|c|}
\hline \multicolumn{7}{|c|}{ Coefficients $^{a}$} \\
\hline & & \multicolumn{2}{|c|}{ Unstandardized Coefficients } & $\begin{array}{l}\text { Standardized } \\
\text { Coefficients }\end{array}$ & $\mathrm{t}$ & Sig. \\
\hline & & & & & & \\
\hline \multirow[t]{4}{*}{1} & (Constant) & 5.972 & 4.643 & & 1.286 & .202 \\
\hline & $\mathrm{XI}$ & .198 & .084 & .218 & 2.351 & .021 \\
\hline & $\mathrm{X} 2$ & .367 & .111 & .316 & 3.311 & .001 \\
\hline & X3 & .374 & .132 & .271 & 2.838 & .006 \\
\hline
\end{tabular}

a. Dependent Variable: Daya Saing

Sumber: data diolah 2020

Tabel 4

Koefisien Determinasi Parsial

\begin{tabular}{|c|c|c|c|c|c|c|c|c|c|}
\hline & \multicolumn{9}{|c|}{ Coefficients $^{a}$} \\
\hline \multirow[t]{2}{*}{ Model } & & \multicolumn{2}{|c|}{$\begin{array}{l}\text { Unstandardized } \\
\text { Coefficients }\end{array}$} & \multirow{2}{*}{$\begin{array}{c}\begin{array}{c}\text { Standardized } \\
\text { Coefficients }\end{array} \\
\text { Beta }\end{array}$} & \multirow[t]{2}{*}{$\mathrm{t}$} & \multirow[t]{2}{*}{ Sig. } & \multicolumn{3}{|c|}{ Correlations } \\
\hline & & $B$ & $\begin{array}{l}\text { Std. } \\
\text { Error }\end{array}$ & & & & $\begin{array}{l}\text { Zero- } \\
\text { order }\end{array}$ & Partial & Part \\
\hline 1 & $\begin{array}{l}\text { (Constan } \\
\text { t) }\end{array}$ & 5.972 & 4.643 & & 1.286 & .202 & & & \\
\hline & $X I$ & .198 & .084 & .218 & 2.351 & .021 & .410 & .246 & .201 \\
\hline & $\mathrm{X} 2$ & .367 & .111 & .316 & 3.311 & .001 & .494 & .336 & .283 \\
\hline & X3 & .374 & .132 & .271 & 2.838 & .006 & .465 & .293 & .243 \\
\hline
\end{tabular}

a. Dependent Variable: Daya Saing

Sumber: Data diolah 2020

Tabel 2

Koefisien Deteminasi Simultan

Model Summary ${ }^{\mathbf{D}}$

\begin{tabular}{lrrrr}
\hline Model & $\mathrm{R}$ & R Square & $\begin{array}{c}\text { Adjusted } \mathrm{R} \\
\text { Square }\end{array}$ & $\begin{array}{c}\text { Std. Error of the } \\
\text { Estimate }\end{array}$ \\
\hline 1 & $.609^{\mathrm{a}}$ & .371 & .349 & 4.3727685 \\
\hline
\end{tabular}

a. Predictors: (Constant), X3, XI, X2

b. Dependent Variable: $Y$

Sumber: Data diolah 2020

dengan demikian $\mathrm{Ha}$ diterima dan $\mathrm{H} 0$ ditolak. Jadi dapat dikatakan bahwa dalam penelitian ini ada pengaruh faktor produksi terhadap daya saing UMK. Hasil uji variabel kondisi permintaan memiliki tingkat signifikansi sebesar 0,001. Tingkat signifikansi yang diperoleh kurang dari 0,05, sedangkan nilai $t_{\text {hitung kondisi permintaan sebesar 3,311 }}$ lebih besar dari $t$ tabel sebesar 1.987, maka dengan demikian $\mathrm{Ha}$ diterima dan $\mathrm{HO}$ ditolak. Jadi dapat dikatakan bahwa ada pengaruh kondisi permintaan terhadap daya saing UMK. Hasil uji t untuk variabel industri terkait dan pendukung diperoleh nilai signifikansi sebesar 0,006 . Tingkat signifikansi yang diperoleh kurang dari 0,05, sedangkan nilai $\mathrm{t}$ hitung industri terkait dan pendukung sebesar 2,838 lebih besar dari t 
tabel sebesar 1.987, maka dengan demikian Ha diterima dan H0 ditolak. Jadi dapat dikatakan bahwa ada industri terkait dan pendukung terhadap daya saing UMK.

Koefisien Determinasi. Koefisien determinasi menunjukkan seberapa besar kombinasi variabel bebas mampu menjelaskan variabel terikat. Berdasarkan tabel 2. Dapat dilihat bahwa besarnya nilai Adjusted $R^{2}$ adalah 0,349. Nilai Adjusted $\mathrm{R}^{2}$ menunjukan $34,9 \%$ daya saing UMK dijelaskan oleh faktor produksi, kondisi permintaan, industri terkait dan pendukung, sedangkan sisanya dijelaskan oleh variabel lain di luar model penelitian.

Pembahasan. Faktor produksi dan peranan sumber daya manusia yang baik akan memberikan kelancaran pada kegiatan usaha. (Cho \& Moon, 2003) "menurut teori ekonomi standar, faktor produksi tenaga kerja, lahan, sumber daya alam, modal, infrastruktur akan menentukan aliran perdagangan". Faktor kondisi yang ada pada Porter Diamond Model dalam penelitian ini dipertegas menjadi, faktor produksi, selain bahan baku juga ada peranan sumber daya manusia. Pada penelitian ini faktor produksi memiliki pengaruh yang paling rendah, hal tersebut sesuai dengan hasil penelitian (Bakan \& Doğan, 2012) The last affective condition is factor condition and it is not a surprise because the competitive advantage is gained with the inimitable qualities of the firms. Hence the factor conditions of the firms are easily imitable by observing and imitating the rival firms. Bahan baku usaha mikro kecil di Provinsi DIY ada produk kerajinan yang bahan bakunya diperoleh dari luar daerah misalnya enceng gondok. Pengusaha, yang manjadi pendiri, pemilik atau manajer dari perusahaan memainkan peran kunci dalam berinovasi dan membuat ide untuk mengatasi masalah dan peluang yang berkembang. Pemerintah DIY khusus- nya Dinas Koperasi dan UMKM telah berusaha memberikan pendidikan nonformal bagi pelaku usaha yang dapat digunakan untuk mengembangkan usahanya. Pendidikan tersebut berwujud pelatihan atau seminar, selain itu melalui Pusat Layanan Usaha Terpadu, pemerintah juga melakukan pendampingan dan konsultasi untuk usaha yang menjadi mitra binaan. Pelaku usaha merasa terbantu dari adanya kegiatan yang dilaksanakan oleh PLUT sehingga memiliki kemampuan untuk menjalankan usaha serta branding.

Kondisi permintaan berkaitan dengan daya saing, dikarenakan pelaku usaha yang dapat mengetahui kondisi permintaan secara baik, maka produknya dapat diterima oleh pasar. Cho dan Moon (2003) menjelaskan mengenai permintaan berkenaan dengan keunggulan, yaitu negara memperoleh keunggulan kompetitif dalam industri di mana permintaan dalam negeri memberi perusahaan suatu gambaran yang lebih jelas atau lebih awal tentang kebutuhan pembeli yang mengemuka, dan di mana para pembeli yang mengajukan permintaan menekan perusahaan untuk berinovasi lebih cepat dan mencapai keunggulan kompetitif yang lebih berpengalaman dibandingkan dengan para pesaing asingnya". Terkait dengan kondisi permintaan, pelaku usaha mitra binaan sudah dapat merespon pasar dengan menyesuaikan sesuatu atau model yang sedang disukai pasar. Permintaan pembeli mendorong perusahaan untuk berinovasi sesuai dengan yang dikemukakan oleh (Molamohamadi et al., 2013) "actually, the request from the customers is a stimulus to the supply chain which makes the focal company to produce their required goods". Demikian halnya deengan Viederyte dan Didziokas (2014) “meeting and identifying the demand of customers will help cluster 
firms to compete more successfully in global

Berdasarkan pendapat tersebut, permintaan pelanggan dapat membantu usaha untuk bersaing melalui identifikasi kebutuhan dari pelanggan. Pengaruh kondisi permintaan terhadap daya saing UMK mitra binaan PLUT sebagai variabel yang dominan mempengaruhi. Hal tersebut sesuai dengan penelitian Bakan dan Dogan (2012), yaitu: the conditions of demand affect the sectors competitiveness more than any other factors in diamond model. UMK DIY sudah menjual pdoduknya sedara online, UMK berusaha untuk mencari daerah pemasaran baru dan menciptakan produk yang bervariasi serta menjaga kualitas produk. Permintaan pembeli juga menunjang perkembangan pasar, sehingga kondisi permintaan berpengaruh terhadap daya saing UMK DIY. Sesuai dengan hasil penelitian Cedrick dan Long (2014:230) konsumen secara tidak langusng terus mendorong pelaku usaha untuk semakin produktif dan inovatif sehingga berdaya saing.

Industri terkait dan pendukung dapat menunjang kelancaran usaha berdasarkan hubungan yang terjalin. UMK telah menyadari pentingnya menjalin kerjasama dengan industri terkait dan pendukung salah satunya yaitu pemasok bahan baku mereka juga merasakan bekerjasama dengan pemasok bahan baku menunjang kelancaran produksi. (Sarach, 2015) "an additional point is that cooperative relationship in clusters stimulates innovation activity, foster progressive technologies and knowledge exchange”. Selain itu pemerintah juga memfasilitasi kios yang disewa di XT-Square untuk pelaku usaha. Jadi, dalam hal ini pemerintah berperan penting dalam menjalin kerjasama dengan usaha. Hal itu sesuai dengan pernyataan (Molamohamadi et al., 2013) "the government is the most influential entity of any focal company as it concerns markets".

about all of the other entities and their rights. It, actually, cares about economic, social, and environmental issues related to the company's operations and activities". Pemerintah memiliki peran penting dalam memperhatikan keberlangsungan UMK. Dari sisi lembaga keuangan, belum banyak pelaku usaha yang memanfaatkan akses ke lembaga keuangan untuk mengembangkan usahanya. Alasannya yaitu mereka merasa cukup dengan modal yang berasal dari pribadi ataupun pinjaman keluarga, selain itu ada juga yang belum mengambil bantuan pemerintah terkait bantuan atau pinjaman modal dengan alasannya yaitu menunggu usaha sehat dan stabil. Media promosi juga mendukung daya saing karena pemanfaatan e-commerce ataupun media sosial sebagai promosi dan penjualan membantu usaha untuk dapat masuk pada pasar yang lebih luas. Industri terkait dan pendukung berpengaruh terhdap daya saing sesuai dengan hasil penelitian (Eickelpasch et al., 2011) "frequent cooperation play a pivotal role in firm innovativeness, i.e. the ability to develop new production methods and/or to introduce new products to the market". Industri terkait dan pendukung memainkan peranan penting dengan mengembangkan metode produksi baru ataupun untuk memperkenalkan produk baru ke pasar.

\section{SIMPULAN}

Kesimpulan. Berdasarkan analisis mengenai faktor produksi, kondisi permintaan, industri terkait dan pendukung terhadap daya saing usaha mikro kecil pada mitra binaan Pusat Layanan Usaha Terpadu di Provinsi Daerah Istimewa Yogyakarta maka dapat diambil kesimpulan sebagai berikut: 
1. Faktor produksi berpengaruh terhadap daya saing UMK

2. Kondisi permintaan berpengaruh terhadap daya saing UMK

3. Kerjasama industri terkait dan pendukung berpengaruh terhadap daya saing UMK

Saran. Berikut saran yang dapat dilakukan oleh pelaku usaha, pemerintah dan penelitian di masa yang akan datang :

1. Variabel faktor produksi memiliki pengaruh paling rendah pada daya saing usaha mikro kecil mitra binaan PLUT, sehingga dibutuhkan bantuan pemerintah dalam peningkatan ketersediaan bahan baku, kemampuan sumber daya manusia, perolehan akses modal serta pemanfaatan teknologi agar UMK lebih dapat berdaya saing.

2. Bagi pelaku usaha, diharapkan terus meningkatkan faktor produksi terutama kemampuan sumber daya manusia dengan terus aktif dalam programprogam yang diselenggarakan oleh PLUT.

3. Bagi peneliti diharapkan dapat melakukan penelitian sejenis dengan lebih memperjelas aspek sumber daya manusia pada faktor produksi sehingga mencerminkan kesesuaian materi yang diberikan dalam seminar atau pelatihan.

\section{DAFTAR PUSTAKA}

Bakan, İ., \& Doğan, İ. (2012). Competitiveness of the industries based on the Porter's diamond model: An empirical study. International Journal of Research and Reviews in Applied Sciences, 11(3), 441455.

Cedrick, B. Z. E., \& Long, W. (2014). Why a Middle Income Country is Experiencing a Booming Auto Industrial Development: Evidence from China and its Meaning for the Developing World. The International Journal Of Business \& Management,2, 225-
233.

http://www.theijbm.com/force_download.p hp?file_path=wpcontent/uploads/2014/11/3 2.BM1409-084.pdf\&id=805.

Cho, D. S., \& Moon, H. C. (2003). From Adam Smith to Michael Porter evolusi teori daya saing. Salemba Empat.

Chosniel, M., Ocloo, E., Akaba, M. S., David, M., \& Worwui-Brown, K. (2014). Globalization and Competitiveness: Challenges of Small and Medium Enterprises (SMEs) in Accra, Ghana. In International Journal of Business and Social Science (Vol. 5, Issue 4).

Darwanto. (2013). Peningkatan Daya Saing Umkm Berbasis Inovasi Dan Kreativitas (Strategi Penguatan Property Right Terhadap Inovasi Dan Kreativitas). Jurnal Bisnis Dan Ekonomi (JBE), 20(2), 142-149. https://media.neliti.com/media/publications/ 24200-ID-peningkatan-daya-saing-umkmberbasis-inovasi-dan-kreativitas-strategipenguatan.pdf.

Eickelpasch, A., Lejpras, A., \& Stephan, A. (2011). Locational and Internal Sources of Firm Competitive Advantage: Applying Porter's Diamond Model at the Firm Level. Journal of Strategic Management Education, 7(2), 1-25.

Fitriati, R. (2015). Menguak daya saing UMKM industri kreatif: sebuah riset tindakan. Yayasan Pustaka Obor Indonesia.

Gautam, R. K., \& Singh, R. (2011). Competitive Perception of Small Indian Manufacturers: A study of Punjab Units. Journal of Competitiveness.

Global Institute of Flexible Systems Management. (2018). Cooperative strategies, innovation capabilities and competitiveness of ventures, International Journal of Global Business and Competitiveness (IJGBC), 9, 1-5. https://fet.unipu.hr/ric/about.

Gupta, S., Malhotra, N. K., Czinkota, M., \& Foroudi, P. (2016). Marketing innovation: A consequence of competitiveness. Journal of Business Research, 69(12), 5671-5681. 
https://doi.org/10.1016/j.jbusres.2016.02.04 2.

Kharub, M., \& Sharma, R. K. (2016). Investigating the role of porter diamond determinants for competitiveness in MSMEs. International Journal for Quality Research, 10(3), 471-486. https://doi.org/10.18421/IJQR10.03-02.

Lantu, D. C., Triady, M. S., Utami, A. F., \& Ghazali, A. (2016). Pengembangan Model Peningkatan Daya Saing UMKM di Indonesia: Validasi Kuantitatif Model. Jurnal Manajemen Teknologi, 15(1), 77-93. https://doi.org/10.12695/jmt.2016.15.1.6.

Mishra, R. (2013). Competitive Strategies for the 21st Century: Theory, History and Practice. Maritime Affairs:Journal of the National Maritime Foundation of India, 9(2), 97-101. https://doi.org/10.1080/09733159.2013.846 965.

Molamohamadi, Z., Ismail, N., Leman, Z., \& Zulkifli, N. (2013). Supplier Selection in a Sustainable Supply Chain. Journal of Advanced Management Science, 278-281. https://doi.org/10.12720/joams.1.3.278-281.

Nagayya, D., \& Tirumala Rao, P. (2013). Small and medium enterprises in the era of globalisation. Journal of Rural Development, 32(1), 1-17.

Porter, M. E. (1990). The Competitive Advantage of Nations Harvard Business Review. Harvard Business Review, 91.

Sarach, L. (2015). Analysis of Cooperative Relationship in Industrial Cluster. Procedia
- Social and Behavioral Sciences, 191, 250254.

https://doi.org/10.1016/j.sbspro.2015.04.27 9.

Shibia, A. G., \& Barako, D. G. (2017). Determinants of micro and small enterprises growth in Kenya. Journal of Small Business and Enterprise Development, 24(1), 105118. https://doi.org/10.1108/JSBED-072016-0118.

Srinivasan, S. K. (2014). Robert Huggins and Hiro Izushi (2011/2012). Competition, Competitive Advantage, and Clusters: The Ideas of Michael Porter (Oxford: Oxford University Press), pp. 303, p/b, ISBN 9780-19-966042-1. IOSR Journal of Business and Management, 16(6), 39-43. https://doi.org/10.9790/487x-16613943.

Tanguy, C. (2016). Cooperation in the food industry: contributions and limitations of the open innovation model. Journal of Innovation Economics, 19(1), 61. https://doi.org/10.3917/jie.019.0061.

Viederyte, R., \& Didziokas, R. (2014). Cluster models, factors and characteristics for the competitive advantage of Lithuanian Maritime sector. ECONOMICS AND MANAGEMENT, 19(2). https://doi.org/10.5755/j01.em.19.2.4197.

Wiyadi, W. (2009). Pengukuran Indeks Daya Saing Industri Kecil Menengah (IKM) di Jawa Tengah. Jurnal Siasat Bisnis, 13(1), 77-92.

https://doi.org/10.20885/jsb.vol13.iss1.art6. 